\title{
The role of mTOR inhibitors in the inhibition of growth and cortisol secretion in human adrenocortical carcinoma cells
}

\author{
Maria Cristina De Martino ${ }^{1,2}$, Peter M van Koetsveld ${ }^{1}$, Richard A Feelders ${ }^{1}$, \\ Diana Sprij-Mooij ${ }^{1}$, Marlijn Waaijers ${ }^{1}$, Steven W J Lamberts ${ }^{1}$, \\ Wouter $W$ de Herder ${ }^{1}$, Annamaria Colao ${ }^{2}$, Rosario Pivonello ${ }^{2}$ and \\ Leo J Hofland ${ }^{1}$
}

${ }^{1}$ Division of Endocrinology, Department of Internal Medicine, Room Ee530b, Erasmus MC, Dr Molewaterplein 50, 3015 GE Rotterdam, The Netherlands

${ }^{2}$ Department of Molecular and Clinical Endocrinology and Oncology, 'Federico II' University, Via Sergio Pansini 5, 80131 Naples, Italy

(Correspondence should be addressed to L J Hofland; Email: I.hofland@erasmusmc.nl)

\begin{abstract}
Patients with adrenocortical carcinoma (ACC) need new treatment options. The aim of this study was to evaluate the effects of the mTOR inhibitors sirolimus and temsirolimus on human ACC cell growth and cortisol production. In H295, HAC15, and SW13 cells, we have evaluated mTOR, IGF2, and IGF1 receptor expressions; the effects of sirolimus and temsirolimus on cell growth; and the effects of sirolimus on apoptosis, cell cycle, and cortisol production. Moreover, the effects of sirolimus on basal and IGF2-stimulated $\mathrm{H} 295$ cell colony growth and on basal and IGF1-stimulated phospho-AKT, phospho-S6K1, and phospho-ERK in H295 and SW13 were studied. Finally, we have evaluated the effects of combination treatment of sirolimus with an IGF2-neutralizing antibody. We have found that H295 and HAC15 expressed IGF2 at a $>1800$-fold higher level than SW13. mTOR inhibitors suppressed cell growth in a dose-/time-dependent manner in all cell lines. SW13 were the most sensitive to these effects. Sirolimus inhibited H295 colony surviving fraction and size. These effects were not antagonized by IGF2, suggesting the involvement of other autocrine regulators of mTOR pathways. In H295, sirolimus activated escape pathways. The blocking of endogenously produced IGF2 increased the antiproliferative effects of sirolimus on $\mathrm{H} 295$. Cortisol production by $\mathrm{H} 295$ and HAC15 was inhibited by sirolimus. The current study demonstrates that mTOR inhibitors inhibit the proliferation and cortisol production in ACC cells. Different ACC cells have different sensitivity to the mTOR inhibitors. mTOR could be a target for the treatment of human ACCs, but variable responses might be expected. In selected cases of ACC, the combined targeting of mTOR and IGF2 could have greater effects than mTOR inhibitors alone.
\end{abstract}

Endocrine-Related Cancer (2012) 19 351-364

\section{Introduction}

Adrenocortical carcinomas (ACC) are uncommon malignancies with an incidence of 1-2 new cases/ million per year (Allolio \& Fassnacht 2006, Fassnacht et al. 2011). ACCs are highly aggressive tumors, associated with a 5-year survival ranging between 37 and $47 \%$, for which novel treatment options are required (Allolio \& Fassnacht 2006, Baudin et al. 2011, Fassnacht et al. 2011).
The insulin-like growth factor (IGF) system is a major actor in the pathogenesis of ACC and is presently considered an attractive target for new treatments in these cancers (Libe \& Bertherat 2005, Almeida et al. 2008, Barlaskar et al. 2009).

mTOR is a protein kinase of the phosphatidylinositol 3-kinase (PI3K)/AKT signaling pathway, functions as a gatekeeper of cell growth, metabolism, and proliferation, receiving signals from sensors of cell stress, 
intracellular nutrient levels, and several growth factor receptors including IGFs and vascular endothelial growth factors (Wan \& Helman 2007, Hanna et al. 2008, Konings et al. 2009). mTOR exists as part of two complexes: mTORC1 and mTORC2, respectively, sensitive or insensitive to rapamycin (sirolimus) (Guertin \& Sabatini 2007). The binding of growth factors to their receptor leads to the phosphorylation and activation of AKT, which elicits many downstream signaling events including the activation of mTOR as part of the mTORC1 complex. Activation of the mTORC1 complex leads to the phosphorylation and activation of downstream effectors of the pathway: the protein 70 ribosomal protein S6 kinase-1 (S6K1 (RPS6KB1)) and eukaryotic translation initiation factor 4E binding proteins (4EBP1 (EIF4EBP1)) (Guertin \& Sabatini 2007). Both S6K1 and 4EBP1 are regulators of mRNA translation and stimulate the synthesis of several proteins involved in cell proliferation (Guertin \& Sabatini 2007).

Alterations in the mTOR pathway have been found in many human tumors, regardless of deregulation of IGF system (Wan \& Helman 2007, LoPiccolo et al. 2008, Konings et al. 2009). Therefore, the mTOR pathway is considered a target for antineoplastic therapy in several malignancies, and it has very recently been proposed as target for ACC treatment (De Martino et al. 2010, Doghman et al. 2010). mTOR inhibitors may exert their antitumor effects directly by inhibiting cell growth and proliferation and indirectly by inhibiting tumor angiogenesis (Guertin \& Sabatini 2007, LoPiccolo et al. 2008).

Presently, many clinical trials are investigating the effects of compounds inhibiting mTORC1 activity (traditional mTOR inhibitors), such as sirolimus, temsirolimus, and everolimus, alone or in combination with other compounds, in several types of malignancy (Wan \& Helman 2007, LoPiccolo et al. 2008, Konings et al. 2009, Liu et al. 2009).

The role and function of mTOR and its pathway in ACC have not been clarified yet (De Martino et al. 2010). Recently, Doghman et al. (2010) showed that mTOR is activated in childhood ACCs and that everolimus is able to inhibit in vitro cell proliferation in ACC cell lines and growth of ACC xenografts in immunodeficient mice.

The aim of this study was to i) evaluate the expression of mTOR, IGF2, and IGF1 receptor (IGF1R) in different human ACC cell lines; ii) test the in vitro effects of the mTOR inhibitors sirolimus and temsirolimus on ACC cell lines in order to understand the mechanism of mTOR inhibitor-induced cell growth inhibition; iii) explore the role of the
IGF2 autocrine loop in the effects of mTOR inhibitors; and iv) evaluate the effect of mTOR inhibitors on cortisol secretion.

\section{Materials and methods}

\section{Study methodology}

In this study, we characterized the expression of the mTOR and IGF2 in three different human ACC cell lines: NCI-H295R (H295), HAC15, and SW13. In H295 and SW13, we also evaluated the expression of IGF1R. In all these cell lines, we tested the dose- and time-dependent effects of sirolimus and temsirolimus on cell growth and the effects of sirolimus on induction of apoptosis and cell cycle. In H295, we tested the effects of sirolimus in the presence and absence of IGF2 stimulation on colony formation and determined the effect of blocking of endogenously produced IGF2 by an IGF2-specific neutralizing antibody on sirolimus-induced cell growth inhibition. In H295 and SW13, we explored the effects of sirolimus on basal and IGF1-induced AKT, ERK1/2, and S6K1 phosphorylation. In the hormonally active ACC cells (H295 and HAC15), the effect of sirolimus on cortisol production was evaluated.

\section{Cell lines and culture conditions}

The hormonally active human ACC cell line H295, its clone HAC15, and the hormonally inactive ACC cell line SW13 were obtained from the American Type Culture Collection (Manassas, VA, USA), from Dr W Rainey (as gift), and from ECACC (Salisbury, Wiltshire, UK) respectively (Wang \& Rainey 2012).

The cells were cultured in $75 \mathrm{~cm}^{2}$ culture flasks at $37{ }^{\circ} \mathrm{C}$ in a humidified incubator at $5 \% \mathrm{CO}_{2}$. For all cell lines, the culture medium consisted of DMEM/F12K medium, supplemented with 5\% FCS, penicillin $\left(1 \times 10^{5} \mathrm{U} / \mathrm{l}\right)$, and L-glutamine $(2 \mathrm{mmol} / \mathrm{l})$. Cells were harvested with trypsin $(0.05 \%)$-EDTA $(0.53 \mathrm{mM})$ and resuspended in culture medium. Cell viability always exceeded $95 \%$. Media and supplements were obtained from Invitrogen.

\section{Drugs and reagents}

mTOR inhibitors sirolimus and temsirolimus were purchased from LC Laboratories, Inc. (Woburn, MA, USA). They were dissolved in dimethylsulfoxide (DMSO) as concentrated $\left(10^{-3} \mathrm{M}\right)$ stock solutions (stored at $-20^{\circ} \mathrm{C}$ ) and diluted in DMSO before use. IGF1 and IGF2 were purchased from Sigma-Aldrich and from Biosource (Tilburg, The Netherlands) 
respectively; both IGFs were diluted in $0.01 \mathrm{M}$ acetic acid solution as concentrated $\left(10^{-5} \mathrm{M}\right)$ stock solutions (stored at $-20^{\circ} \mathrm{C}$ ) and diluted in medium before use.

Anti-IGF2-neutralizing antibody (m610 human monoclonal antibody to IGF2) was kindly provided by Drs Dimiter Dimitrov and Yang Feng (Feng et al. 2006).

\section{Quantitative RT-PCR}

The expression of mTOR and IGF2 mRNA in human ACC cells was evaluated by quantitative RT-PCR.

From human ACC cell lines, total RNA was isolated using a commercially available kit (High Pure RNA Tissue kit; Roche). cDNA was synthesized using $500 \mathrm{ng}$ total RNA in a Super Reverse Transcriptase (RT) buffer (HT Biotechnology Ltd., Cambridge, UK), together with $40 \mathrm{nmol}$ of each deoxynucleotide triphos phate, $15 \mathrm{ng}$ oligo-dT primer, $20 \mathrm{U}$ RNAse inhibitor, and $4 \mathrm{U}$ AMV/Super RT (HT Biotechnology) in a final volume of $40 \mu \mathrm{l}$. This mixture was incubated for $1 \mathrm{~h}$ at $40{ }^{\circ} \mathrm{C}$ and thereafter five times diluted in bidest. A quantitative PCR was performed by TaqMan Gold nuclease assay (Perkin Elmer Corporation, Foster City, CA, USA) and the ABI-PRISM-7900 sequence Detection System (Perkin Elmer, Groningen, The Netherlands) for real-time amplifications, according to the manufacturer's protocol. The assay was performed using 7.5 $\mu 1$ TaqMan Universal PCR Master Mix (Applied Biosystems, Alphen a/d Ryn, The Netherlands), primers and probes amount as reported in supplementary materials 1 and $5 \mu \mathrm{l}$ cDNA template, in a total reaction volume of $12.5 \mu \mathrm{l}$. After an initial heating at $50{ }^{\circ} \mathrm{C}$ for $2 \mathrm{~min}$ and $95^{\circ} \mathrm{C}$ for $10 \mathrm{~min}$, samples were subjected to 40 cycles of denaturation at $95^{\circ} \mathrm{C}$ for $15 \mathrm{~s}$ and annealing for $1 \mathrm{~min}$ at $60{ }^{\circ} \mathrm{C}$. The primers and probes were purchased from SigmaAldrich. The sequence of the primers and probes used are reported in supplementary material 1. Samples were normalized against the expression of the housekeeping gene hypoxanthine phosphoribosyltransferase 1 (HPRT (HPRT1)). PCR efficiencies (E) were calculated for the primer-probe combinations used (supplementary material 1) (Rasmussen 2001). The relative expression of genes was calculated using the comparative threshold method, $2^{-\Delta C_{\mathrm{t}}}$ (Schmittgen \& Livak 2008), after efficiency correction (Pfaffl 2001) of target and reference gene transcripts (HPRT).

\section{Immunohistochemistry: AgarCyto cell block}

The expression of mTOR and IGF2 proteins in human ACC cell lines was evaluated by immunohistochemistry using AgarCyto cell blocks. H295, HAC15, and
SW13 cell pellets were fixed in $4 \%$ formaldehyde solution in PBS, embedded in 2\% agarose and afterward in paraffin (Kerstens et al. 2000). AgarCyto cell blocks were cut in $5 \mu \mathrm{m}$ sections, deparaffinized, and dehydrated. Antigen retrieval was performed by microwave treatment in Tris-EDTA buffer ( $\mathrm{pH}$ 9.0). The slides were cooled for $1 \mathrm{~h}$ at $+4{ }^{\circ} \mathrm{C}$ and later incubated for $1 \mathrm{~h}$ at room temperature (RT) with the anti-mTOR primary antibodies or overnight at $+4{ }^{\circ} \mathrm{C}$ with the anti-IGF2 primary antibodies. The slides incubated with anti-IGF2 antibodies were subsequently washed and incubated for $30 \mathrm{~min}$ at RT with PolyRabbit anti-Goat IgG. The slides were further washed and incubated for $30 \mathrm{~min}$ at RT with Poly-AP-Goat anti-Mouse/Rabbit IgG. After washing, staining was visualized by $30 \mathrm{~min}$ incubation in new fuchsin solution. Slides were counterstained with hematoxylin and coverslipped. The antibody and the controls used are listed in supplementary material 2 .

\section{Immunocytochemistry: chamber slides}

Cells were plated on poly-L-lysine-coated culture chamber slides (NUNC A/S, Roskilde, Denmark). After $48 \mathrm{~h}$, medium was removed and cells were fixed with $4 \%$ paraformaldehyde and $0.2 \%$ picric acid in phosphate buffer, $\mathrm{pH} 6.9$, for $40 \mathrm{~min}$ at RT. After washing, the cells were treated for 3 min with $50 \%$ methanol and for 3 min with $100 \%$ methanol. After another washing, the cells were treated with a $3 \% \mathrm{H}_{2} \mathrm{O}_{2}-\mathrm{PBS}$ solution for $15 \mathrm{~min}$ at $\mathrm{RT}$ in the dark to quench endogenous peroxidase. After washing, the cells were incubated for $1 \mathrm{~h}$ at RT with an IGF1R monoclonal antibody (supplementary material 2). Finally, the cells were incubated for $30 \mathrm{~min}$ at RT with HRP/anti-Rabbit/ Mouse (Dako Detection System). Bound antibodies were visualized by incubation with freshly prepared DAB (Dako Detection System). Slides were counterstained with hematoxylin and coverslipped. For negative controls, the primary antibody was omitted.

\section{Cell proliferation assay}

\section{Measurement of total DNA content}

Cells were plated in $1 \mathrm{ml}$ medium in 24-well plates at the density necessary to obtain a $65-70 \%$ cell confluence in the control groups at the end of the experiment. Twenty-four hours later, sirolimus or temsirolimus were added to wells in quadruplicate. The concentrations of compounds tested in H295 and HAC15 ranged between $10^{-9}$ and $10^{-5} \mathrm{M}$. In the SW13, a maximal effect of compounds was observed already at $10^{-8} \mathrm{M}$. Therefore, we tested concentrations of compounds ranged between $10^{-12}$ and $10^{-8} \mathrm{M}$. 
Controls were vehicle treated. The cells inoculated for 6 and 9 days were refreshed every 3 days by adding fresh compounds. After 24 h, 3, 6, and 9 days of treatment, the cells were harvested for DNA measurement, as a measure of cell number. Measurement of total DNA content was previously described in detail (Hofland et al. 1990).

\section{Cell proliferation reagent WST-1 (WST)}

In H295 cells, the effect of IGF2-specific neutralizing antibody on sirolimus-induced inhibition of cell proliferation was determined by WST-1 assay (Cell Proliferation Reagent WST-1 (Roche)) according to the protocol provided by the manufacturer. Cells were plated in $100 \mu \mathrm{l}$ medium $+5 \%$ FCS (standard medium) in 96-well plates (20000 cells/well). After $24 \mathrm{~h}$, the medium was changed with medium $+1 \%$ FCS and the following reagents were added: vehicle, sirolimus $\left(10^{-9} \mathrm{M}\right)$, anti-IGF2 $\left(4 \times 10^{-8} \mathrm{M}\right)$, and sirolimus + anti-IGF2. After $72 \mathrm{~h}$, cell proliferation was measured by WST-1 assay. The experiment was repeated twice, and each experiment was performed in quadruplicate.

\section{DNA fragmentation assay}

DNA fragmentation assay was used to determine the effects of the compounds on apoptosis. The cells were plated in 24-well plates and treated as described earlier for the cell proliferation assay. After $24 \mathrm{~h}$ and 3 days of incubation, DNA fragmentation was determined using a commercially available ELISA kit (Roche Diagnostic $\mathrm{GmbH})$. The standard protocol supplied by the manufacturer was used. The same plates were also analyzed for the measurement of total DNA content. The amount of DNA fragmentation (apoptosis) was corrected for the total DNA content in each well.

\section{Cortisol secretion assay}

In H295 and HAC15, we evaluated the effects of sirolimus on cortisol production. The cells were plated in 24-well plates and treated for 6 days as described earlier for the cell proliferation assay. We tested the effects of the sirolimus on cortisol production in concentrations corresponding to the $\mathrm{EC}_{50}$ on cell proliferation after 6 days of treatment. The culture supernatants from experiment performed in $\mathrm{H} 295$ and $\mathrm{HAC} 15$ cells were collected and stored at $-20{ }^{\circ} \mathrm{C}$ until determination of the cortisol concentration.

The cortisol concentration was determined by a nonisotopic, automated chemiluminescence immunoassay system (Siemens Medical Solutions Diagnostics, Breda, The Netherlands). Cortisol levels were expressed as percentage of control and were corrected for the total DNA content in each well, thereby reflecting cortisol production per cell.

\section{Cell cycle analysis}

Cells were plated in 12-well plates at the density necessary to obtain a $65-70 \%$ cell confluence in the control groups at the end of the experiment. Twentyfour hours later, sirolimus was added to wells in triplicate. In each cell line, the effects of sirolimus on cell cycle were tested in concentrations corresponding to the $\mathrm{EC}_{50}$ on cell proliferation after 6 days of treatment. In addition, the effects of the compounds at concentrations of $10^{-6} \mathrm{M}$ in H295 and HAC15 and $10^{-8} \mathrm{M}$ in SW13 were tested. Control groups were vehicle treated. We evaluated the effects of the compounds on cell cycle after $24 \mathrm{~h}$ of treatment in SW13 and in H295 and HAC15 cell lines after $72 \mathrm{~h}$ of treatment according to the different growth rates of these cells. Following treatment, cells were harvested by gentle trypsinization, washed with ice-cold PBS, and collected by centrifugation. Cells were resuspended in $200 \mu \mathrm{l} \mathrm{PBS}$ and fixed in $70 \%$ ice-cold ethanol, followed by an overnight incubation at $-20^{\circ} \mathrm{C}$. After centrifugation, the cells were washed once with PBS and incubated for $30 \mathrm{~min}$ at $37^{\circ} \mathrm{C}$ in PBS containing $40 \mu \mathrm{g} / \mathrm{ml}$ propidium iodide (SigmaAldrich) and $10 \mu \mathrm{g} / \mathrm{ml}$ DNase-free RNase (SigmaAldrich). For each tube, 20000 cells were immediately measured on a FACScalibur flow cytometer (Becton Dickinson, Erembodegem, Belgium) and analyzed using CellQuest Pro Software.

\section{Colony-forming assay}

Cells were plated in poly-L-lysine $(10 \mu \mathrm{g} / \mathrm{ml}$; SigmaAldrich)-coated 12-well plates (2500 cells/well) and cultured in complete medium for 3 weeks.

Cells were allowed to attach for $24 \mathrm{~h}$ before to be treated with the vehicle, sirolimus $\left(5 \times 10^{-9} \mathrm{M}\right)$, IGF2 $\left(10^{-8} \mathrm{M}\right)$, or the combination of the two compounds. The experiment has been performed two times in triplicate. Cells were treated continuously and medium plus the compounds were refreshed every 3 or 4 days. After 3 weeks, the formed colonies were fixed with $100 \%$ ethanol and stained with hematoxylin to allow calculation of the average colony-forming efficiency. Colonies containing more than 50 cells were automatically counted with a Multi Image Light Cabinet from Alpha Innotech Corporation (Cell Biosciences, San Leandro, CA, USA).

Plating efficiency was defined as the mean number of colonies formed divided by the number of plated cells for control cultures expose to the vehicle express 
as percentage. The surviving fraction (SF) was calculated as (mean number of colonies)/(number of plated cells $\times$ plating efficiency) (Franken et al. 2006).

\section{Protein extraction}

H295 and SW13 cells were plated in $3 \mathrm{ml}$ medium in six-well plates at the density required to obtain $65-70 \%$ cell confluence at the end of the experiment. Seventy-two hours later, cells were starved for $12 \mathrm{~h}$ and then incubated for $1 \mathrm{~h}$ with sirolimus or vehicle. The final concentrations of sirolimus tested were $10^{-6} \mathrm{M}$ and $5 \times 10^{-9} \mathrm{M}$ in $\mathrm{H} 295$ and $10^{-8}$ and $10^{-10} \mathrm{M}$ in SW13. Thirty minutes before collection of cells, IGF1 $\left(10^{-8} \mathrm{M}\right)$ was added to selected wells. Cells were washed with ice-cold PBS. Whole-cell lysates were prepared by adding $200 \mu \mathrm{l}$ ice-cold RIPA lysis buffer (Pierce Biotechnology, Inc., Rockford, IL, USA) with the addition of $1 \%$ Halt Phosphatase Inhibitor Cocktail (Pierce Biotechnology, Inc.) to each well. After $1 \mathrm{~min}$ of incubation on ice, the cell lysates were transferred to the labeled tubes. After $15 \mathrm{~min}$ of incubation on ice (mixing every $5 \mathrm{~min}$ ), the samples were spun down at $18000 \mathrm{~g}$ at $4{ }^{\circ} \mathrm{C}$. The supernatants were stored at $-80^{\circ} \mathrm{C}$.

The total amount of proteins was calculated with dye-binding assay (Bio-Rad Protein Assay), using BSA as standard curve and a spectrophotometer set to $595 \mathrm{~nm}$ as reader.

\section{Western blotting}

Total protein solution $(30 \mu \mathrm{g})$ diluted in a water solution containing $20 \%$ SDS sample buffer was denatured $\left(5 \mathrm{~min}\right.$ in a bath at $\left.95^{\circ} \mathrm{C}\right)$ and separated by electrophoresis on 10\% SDS-PAGE gel and transferred to a nitrocellulose membrane. The membranes were first incubated for $2 \mathrm{~h}$ with blocking buffer $(0.1 \%$ Tween 20-PBS/5\% BSA for membranes for AKT measurement and $0.1 \%$ Tween $20-\mathrm{PBS} / 3 \%$ nonfat dry milk for the remaining membranes) and subsequently incubated overnight at $4{ }^{\circ} \mathrm{C}$ with the primary antibody (supplementary material 3 ). After $1 \mathrm{~h}$ of washing in $0.1 \%$ Tween $20-\mathrm{PBS}$, the membranes were incubated for $1 \mathrm{~h}$ with the secondary antibody at room temperature, followed by $1 \mathrm{~h}$ wash in $0.1 \%$ Tween 20-PBS. Starting from the incubation with the secondary antibodies, the membranes were preserved in dark condition. Immunodetection was performed using the Odyssey infrared imaging system (LI-COR Biosciences, Cambridge, UK). The optical density of the appropriately sized bands was measured using the Odyssey molecular imaging software (LI-COR Biosciences). The relative expression of total AKT, total S6K, or total ERK was calculated as a ratio to the expression of actin. The relative expression of phospho-AKT, phospho-S6K, or phospho-ERK was calculated as a ratio to total AKT, S6K, or ERK respectively.

\section{Statistical analysis}

All the experiments were carried out at least three times, with the exception of colony-forming assay and the WB that were performed twice. The repeated experiments gave comparable results. For the statistical analysis, statistical software of SPSS (SPSS 15.0; SPSS, Inc., Chicago, IL, USA) and GraphPad Prism 5.0 (GraphPad Software, San Diego, CA, USA) were used.

We used nonparametric tests to evaluate the differences among groups (Mann-Whitney and Kruskal-Wallis tests).

The comparative statistical evaluations among treatment groups were performed by ANOVA followed by a multiple comparative test (NewmanKeuls or Dunnett's test).

\section{Results}

\section{Expression of mTOR IGF2 and IGF1R in ACC cell lines}

The IGF2 mRNA levels in $\mathrm{H} 295$ and HAC15 $(\mathrm{H} 295=59.3 \pm 31 ; \mathrm{HAC} 15=50.6 \pm 9$; ration over HPRT, mean \pm S.D.) cells were more than 1800 -fold higher $(P<0.001)$ than in SW13 in which $I G F 2$ mRNA was just detectable $(0.03 \pm 0.03$; mean \pm s.D. $)$, whereas the mRNA expression levels of mTOR were comparable between the cell lines $(\mathrm{H} 295=0.12 \pm 0.05$; $\mathrm{HAC} 15=0.12 \pm 0.08 ; \quad \mathrm{SW} 13=0.14 \pm 0.06)$. The higher expression levels of IGF2 in H295 and HAC15 compared with SW13 were also confirmed at protein level by immunostaining (Fig. 1). In addition, the mTOR immunostaining showed a strong positivity in all cell lines (Fig. 1). A positive immunoreactivity for IGF1R was shown in both H295 and SW13 cell lines (Fig. 2).

\section{Effects of mTOR inhibitors on cell growth and apoptosis in ACC cell lines}

In ACC cell lines, sirolimus and temsirolimus significantly suppressed the cell growth in a doseand time-dependent manner (Fig. 3 shows the effects in H295 and SW13; effects in HAC15 are shown in supplementary Fig. 1). 

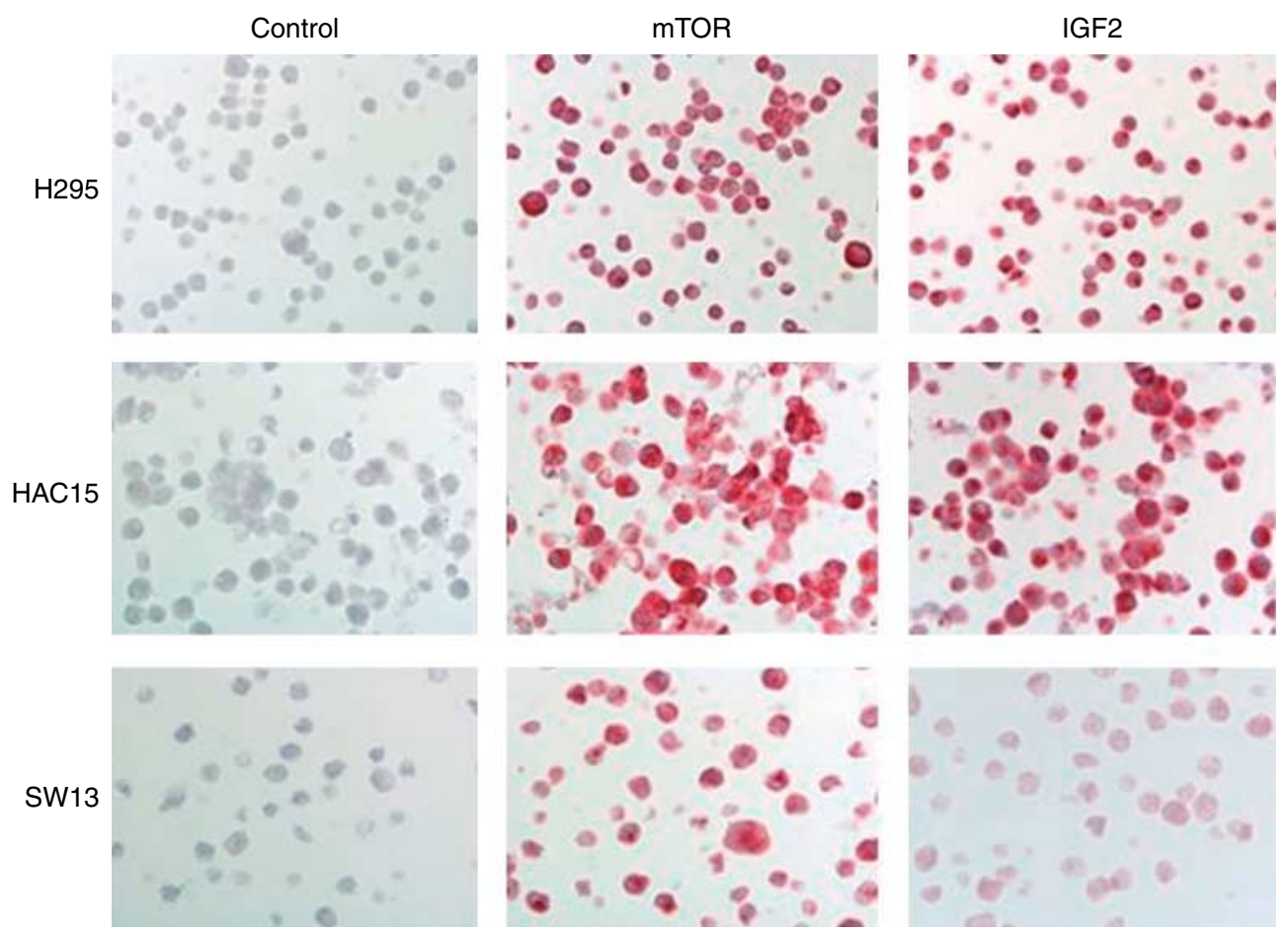

Figure 1 Immunocytochemical detection of mTOR (middle panel) and IGF2 (right panel) in human ACC cell lines. Left panel shows the absence of staining in the negative controls. Magnification, $\times 100$.

In H295, both compounds were able to significantly inhibit the cell growth with a comparable potency after 9 days of treatment $\left(\mathrm{EC}_{50}: 4.8 \times 10^{-9}\right.$ vs $1.9 \times$ $\left.10^{-8} \mathrm{M}\right)$. The effects of sirolimus ranged between
$61.7 \%$ inhibition $(P<0.001)$ at the maximal dose $\left(10^{-5} \mathrm{M}\right)$ and $16.7 \%(P<0.01)$ at the minimal dose tested $\left(10^{-9} \mathrm{M}\right)$. The effects of temsirolimus ranged between $57.1 \%$ inhibition $(P<0.001)$ at the maximal
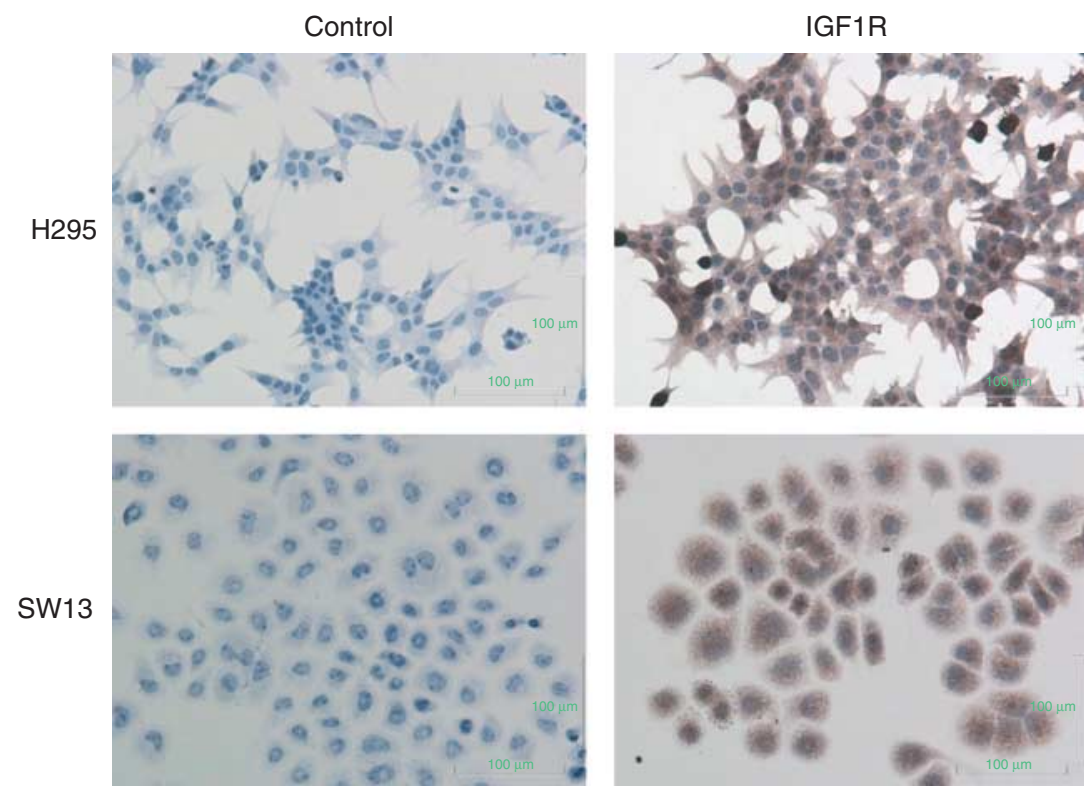

Figure 2 Immunocytochemical detection of IGF1R (right panel) in the human ACC cell lines H295 and SW13. Left panel shows the absence of staining in the negative controls. Magnification, $\times 200$. 

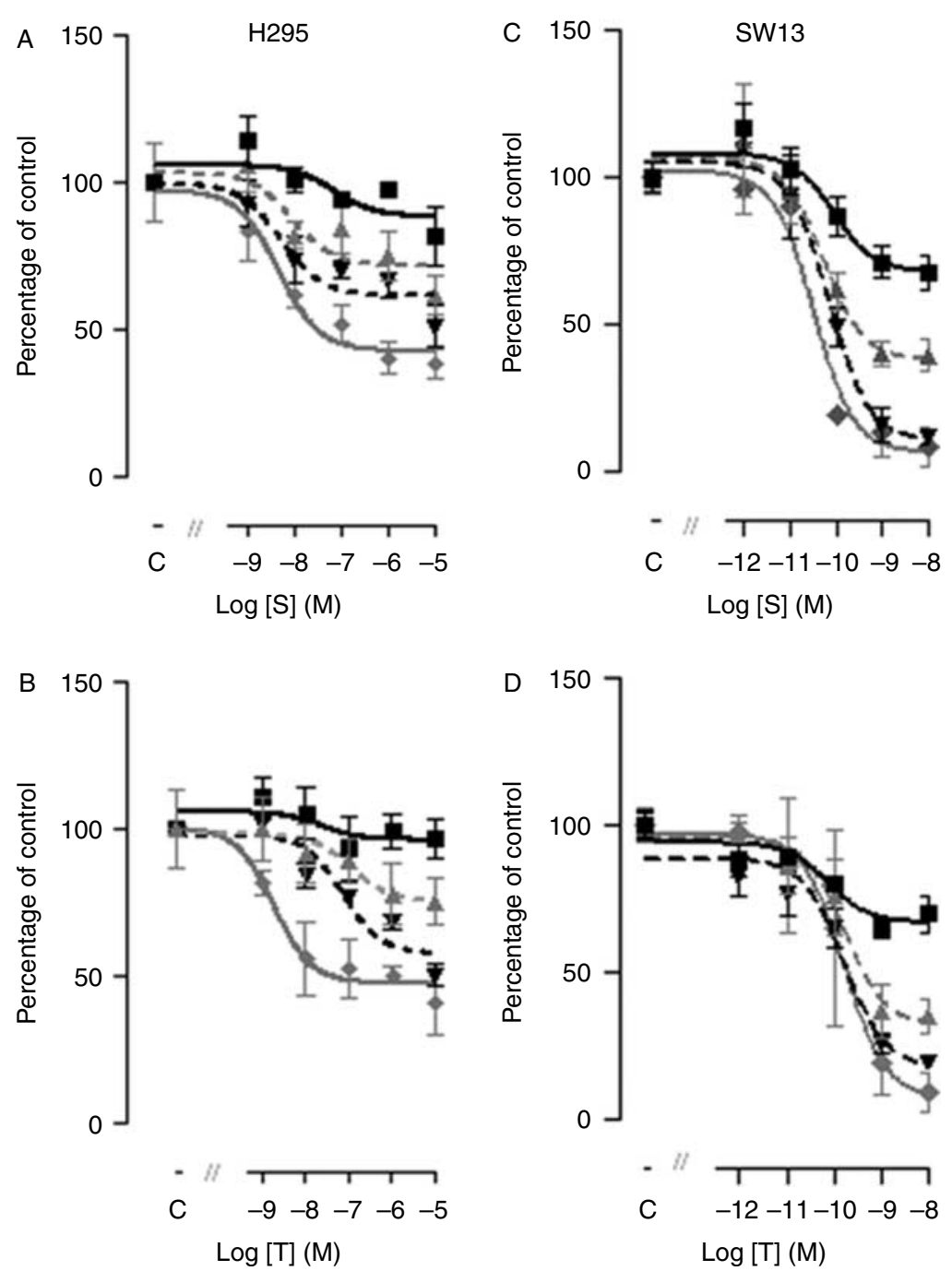

Figure 3 Dose-/time-dependent effect of sirolimus (S; panels A and C) and temsirolimus (T, panels B and D) treatment on cell proliferation, expressed as DNA content/well after $24 \mathrm{~h}$ (closed square), 3 days (closed triangle), 6 days (closed down triangle), and 9 days (closed diamond) treatment in H295 (left panels) and SW13 (right panels) cells. Data are expressed as the percentage of control and represent the mean \pm S.D. Control is set as $100 \%$.

dose $\left(10^{-5} \mathrm{M}\right)$ and $16 \%(P<0.05)$ at the minimal dose tested $\left(10^{-9} \mathrm{M}\right)$.

In HAC15, both compounds were able to significantly inhibit the cell growth with a comparable potency after 9 days of treatment $\left(\mathrm{EC}_{50}: 1.4 \times 10^{-8} \mathrm{vs}\right.$ $\left.4.3 \times 10^{-7} \mathrm{M}\right)$. The effects of sirolimus ranged between $79.9 \%$ inhibition $(P<0.001)$ at the maximal dose $\left(10^{-5} \mathrm{M}\right)$ and $24.4 \%(P<0.05)$ at the minimal dose tested $\left(10^{-9} \mathrm{M}\right)$. The effects of temsirolimus ranged between $81 \%$ inhibition $(P<0.001)$ at the maximal dose $\left(10^{-5} \mathrm{M}\right)$ and $24.6 \%(P<0.05)$ at the minimal dose tested $\left(10^{-9} \mathrm{M}\right)$.

Nine days of treatment with sirolimus (Fig. 3C) and temsirolimus $10^{-10} \mathrm{M}$ were already able to significantly inhibit the cell growth of SW13 cells.
Sirolimus was significantly more potent than temsirolimus in terms of $\mathrm{EC}_{50}\left(\mathrm{EC}_{50}: 3.3 \times 10^{-11}\right.$ vs $\left.1.7 \times 10^{-10} \mathrm{M} ; P=0.02\right)$ but not with respect to the maximal and the minimal effective concentration of the two compounds. The effects of sirolimus ranged between $91.7 \%$ inhibition $(P<0.001)$ at the maximal dose $\left(10^{-8} \mathrm{M}\right)$ and $49.3 \%(P<0.05)$ at the dose of $10^{-10} \mathrm{M}$. The effects of temsirolimus were ranged between $91.5 \%$ inhibition $(P<0.001)$ at the maximal dose $\left(10^{-8} \mathrm{M}\right)$ and $34.9 \%(P<0.05)$ at the dose of $10^{-10} \mathrm{M}$.

In $\mathrm{H} 295$, sirolimus was able to significantly induce DNA fragmentation only at the highest dose used $\left(10^{-5} \mathrm{M}\right)$ (Fig. 4). Sirolimus $\left(10^{-5} \mathrm{M}\right)$ was able to induce apoptosis also in HAC15. These effects were 

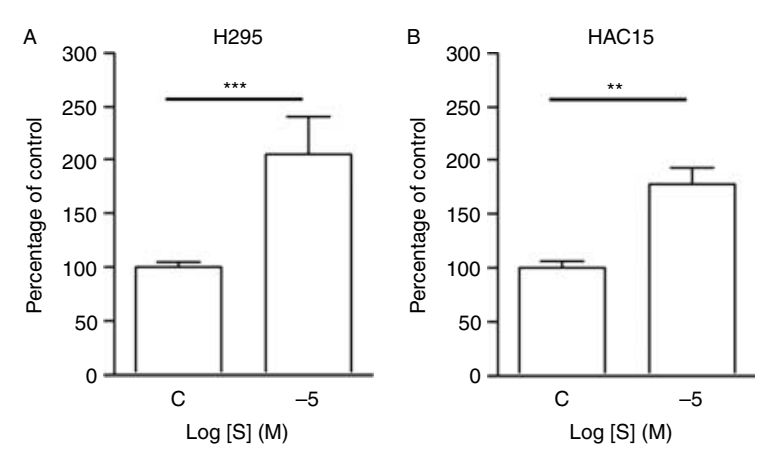

Figure 4 Twenty-four hour treatment with sirolimus at high dose $\left(10^{-5} \mathrm{M}\right)$ was able to induce cell apoptosis, as measured by the induction of DNA fragmentation, in H295 (A) and HAC15 (B) cells. Data are expressed as percentage of control and represent the mean \pm S.D. Control is set as $100 \%$. ${ }^{* \star} P<0.01$; ${ }^{* * *} P<0.001$ vs control.

more pronounced after $24 \mathrm{~h}$ than after 3 days of treatment. At the doses tested $\left(10^{-8}\right.$ to $\left.10^{-12} \mathrm{M}\right), 24 \mathrm{~h}$ and 3 days of treatment, sirolimus was not able to significantly induce apoptosis in SW13 (not shown).

\section{Effects of sirolimus on cortisol secretion in ACC cell lines}

Sirolimus induced a significant inhibition of cortisol secretion in H295 and HAC15. These effects were still present after the correction for the estimated cell number in each well, suggesting a direct effect of sirolimus on hormonal secretion in ACC cells (Fig. 5). Cortisol secretion was inhibited by $21.7 \%$ in the $\mathrm{H} 295$ sirolimus $\left(5 \times 10^{-9} \mathrm{M}\right)$-treated cells $(P<0.01)$ (Fig. 5A) and by $41.3 \%$ in sirolimus $\left(10^{-8} \mathrm{M}\right)$-treated HAC15 cells $(P<0.001)$ (Fig. 5B).

\section{Effects of sirolimus on cell cycle progression and colony formation in ACC cell lines}

To explore the mechanisms involved in mTOR inhibitor-induced inhibition of cell proliferation, we performed FACS analysis and colony-forming assay. At FACS analysis, sirolimus $\left(10^{-6} \mathrm{M}\right)$ induced a significant G1-phase arrest in $\mathrm{H} 295$ and HAC15 (Table 1). In SW13, we observed a significant G1-phase arrest by sirolimus at $10^{-8}$ and $10^{-10} \mathrm{M}$ (Table 1). This effect at the highest concentration of compound used was accompanied by a decrease in S-phase and G2-phase (Table 1).

The plating efficiency for $\mathrm{H} 295$ in colony forming was $8.6 \%$. Three weeks of treatment with sirolimus $5 \times 10^{-9} \mathrm{M}$ significantly inhibited the formation and growth of colonies as measured by a reduced SF (69.9\% vs control; $P<0.001)$ and average colony size (56.6\%; $P<0.001$ ) (Fig. 6). IGF2 $10^{-8} \mathrm{M}$ was able to significantly increase the colony growth by increasing their size $(62.7 \% ; P<0.001)$ and the SF $(29 \%$; $P<0.05)$. At the condition tested, the effects of sirolimus on SF and colony size were not reverted by the coadministration of IGF2. Similar results were also obtained when we repeated the experiment using IGF2 $5 \times 10^{-8} \mathrm{M}$ (results not shown).

\section{Effects of sirolimus on the IGF-activated intracellular pathways in ACC cells}

To further understand the mechanisms responsible for the effects of the mTOR inhibitor in ACC cell lines, we studied the effects of sirolimus and/or IGF1 on some key intracellular components of the IGF pathway in H295 and SW13 (Fig. 7). Thirty minutes of IGF1 $\left(10^{-8} \mathrm{M}\right)$ stimulation significantly increased the phosphorylation of S6K1 and AKT in both cell lines. IGF1 stimulation increased the phosphorylation of ERK1/2 in H295. H295 cells treated with sirolimus $10^{-6}$ and $5 \times 10^{-9} \mathrm{M}$ had significantly lower phospho/ total S6K1 than control and IGF1-stimulated cells, as expected by a successful inhibition of the mTORC1 complex activity. Sirolimus $\left(10^{-8}\right.$ and $\left.10^{-10} \mathrm{M}\right)$ reduces phospho/total S6K1 also in SW13, but this reduction resulted statistically significant only when compared with the IGF1-stimulated cells and not when compared with the control (12 h starved cells). In both cell lines, the sirolimus-induced inhibition of S6K1 phosphorylation was not reverted by the IGF1 stimulation. In $\mathrm{H} 295$, the treatment with sirolimus was associated with an increased AKT phosphorylation and this AKT stimulation was enhanced by the IGF1 stimulation. In SW13, the treatment with sirolimus alone did not increase the AKT phosphorylation. However, an increased phospho/total AKT was observed in all IGF1-stimulated cells, despite the sirolimus treatment. In SW13, the ERK1/2 phosphorylation was not affected by the IGF1 and/or sirolimus treatment.

\section{Effect of IGF2 neutralization on sirolimus-induced H295 cell growth inhibition}

To better address the potential influence of the IGF2 autocrine loop on ACC cell sensitivity to the mTOR inhibitors, we tested the effects of sirolimus $\left(10^{-9} \mathrm{M}\right)$ on cell growth in the presence or absence of anti-IGF2 neutralizing antibodies $\left(4 \times 10^{-8} \mathrm{M}\right)$. This concentration of anti-IGF2 was previously shown to completely block IGF2 $\left(10^{-8} \mathrm{M}\right)$-induced cell proliferation (Feng et al. 2006). FCS medium (1\%) was used to minimize the presence of exogenous growth factors. In these conditions, a $72 \mathrm{~h}$ treatment 
A

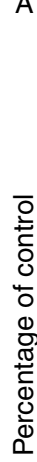

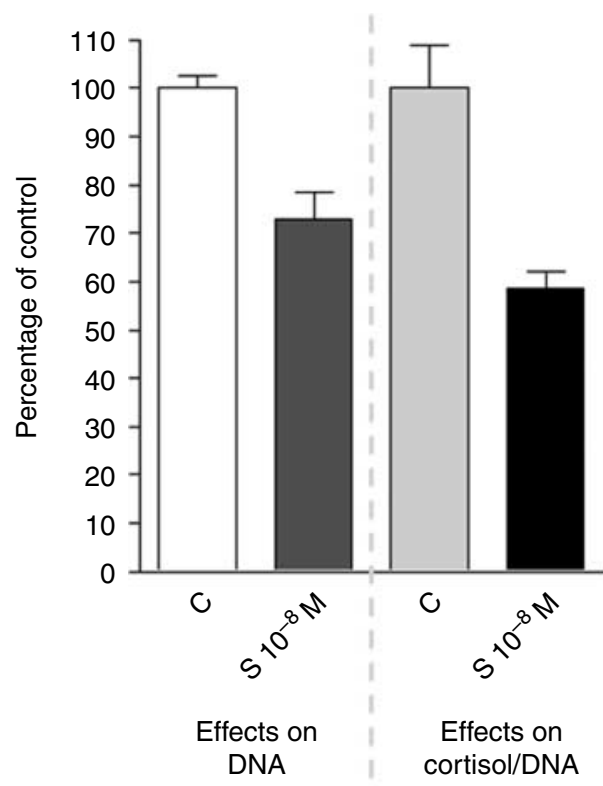

Figure 5 Six-day treatment with sirolimus inhibits cortisol production in ACC cells H295 (A) and HAC15 (B) independently of the inhibition of cell proliferation. The graphs show in parallel the effects of sirolimus on the cell proliferation (total DNA content) and on cortisol production for both cell types. The dose of sirolimus used $\left(5 \times 10^{-9} \mathrm{M}\right.$ in $\mathrm{H} 295$ and $10^{-8} \mathrm{M}$ in HAC15) corresponded at the $\mathrm{EC}_{50}$ of cell growth inhibition in each cell type. The cortisol levels measured were normalized for the total number of cells present in each well (Cortisol/total DNA content). Data are expressed as percentage of control and represent the mean \pm s.D. Control is set as $100 \%$. with sirolimus combined with anti-IGF2 Abs was able to almost totally block $\mathrm{H} 295$ cell proliferation (90\% inhibition compared with controls). Sirolimus or antiIGF2 antibody alone induced an inhibition in H295 cell proliferation of 64 and $42 \%$ respectively (Fig. 8).

\section{Discussion}

In this study, we describe the expression of mTOR, IGF2, and IGF1R and the in vitro antiproliferative and antisecretive effects of the mTOR inhibitors in the currently available human ACC cell lines. All ACC cell lines expressed comparable mRNA and protein mTOR levels. Both H295 and SW13 showed a significant IGF1R protein expression. Conversely, the expression levels of IGF2 were considerably higher in $\mathrm{H} 295$ and its clone HAC15 than those in SW13. These results show that mTOR is expressed in human ACC cell lines and its expression appears to be unrelated to $I G F 1 R$ expression or $I G F 2$ overexpression.

The mTOR inhibitors caused a significant inhibition of cell growth in vitro and sirolimus induced a significant reduction of hormonal production in the hormonally active cells, independent of the effect on cell growth. Sirolimus appeared to be more potent than temsirolimus in inhibiting cell proliferation in SW13. Temsirolimus acts as direct inhibitor of mTOR, but in vivo temsirolimus is also converted in sirolimus (Atkins et al. 2004). After having proven that temsirolimus inhibits the in vitro cell growth in ACC cell lines also in a direct way, we continued the experiments using sirolimus only. Cell cycle arrest appeared the predominant mechanism responsible for the observed antiproliferative effects of sirolimus, as already reported in other cancer cell lines (Huang \& Houghton 2002).

In H295 and SW13, IGF1 stimulation has been correlated with increased AKT phosphorylation (Cantini et al. 2008, Barlaskar et al. 2009). In this study, we describe an IGF1-induced AKT and S6K1 phosphorylation in both ACC cell lines confirming the role of the AKT/mTOR pathway as intracellular mediator of the IGF signaling in ACCs. Moreover, we prove that long-term exposure to IGF2 promotes colony growth in $\mathrm{H} 295$ and these effects are antagonized by mTOR inhibitors. It has been reported that everolimus can produce antivascular effects in in vivo model ACCs (Doghman et al. 2010). Therefore, mTOR plays a role as intracellular mediator of the autocrine/paracrine loops considered to be involved in the pathogenesis of ACCs (Volante et al. 2008, De Martino et al. 2010).

In this study, we found that the different ACC cell lines display a differential sensitivity to the antigrowth 
Table 1 Effects of sirolimus on cell cycle distribution in mean \pm s.D. in human adrenocortical cancer cell lines (H295, HAC15, and SW13)

\begin{tabular}{|c|c|c|c|c|}
\hline & Phase sub Go & Phase G0/1 & Phase S & Phase G2/M \\
\hline \multicolumn{5}{|l|}{ H295 } \\
\hline Control & $2.9 \pm 0.6$ & $55.8 \pm 5.1$ & $12.4 \pm 2.8$ & $27.8 \pm 3.7$ \\
\hline Sirolimus $10^{-6} \mathrm{M}^{\mathrm{a}}$ & $2.8 \pm 0.7$ & $59.4 \pm 3.8^{*}$ & $11.3 \pm 2.9$ & $26.4 \pm 3.8$ \\
\hline Sirolimus $5 \times 10^{-9} \mathrm{M}^{\mathrm{a}}$ & $3.9 \pm 1.8$ & $55.9 \pm 4$ & $11.6 \pm 1.4$ & $28.6 \pm 4.2$ \\
\hline \multicolumn{5}{|l|}{ HAC15 } \\
\hline Control & $7.8 \pm 2.9$ & $60.7 \pm 1.5$ & $15.7 \pm 0.9$ & $15.8 \pm 3.4$ \\
\hline Sirolimus $10^{-6} \mathrm{M}^{\mathrm{a}}$ & $6.8 \pm 1.5$ & $63.8 \pm 2.3^{*}$ & $14.2 \pm 1.6$ & $15.3 \pm 2$ \\
\hline Sirolimus $10^{-8} \mathrm{M}^{\mathrm{a}}$ & $8 \pm 2.2$ & $61.6 \pm 1.9$ & $15.6 \pm 1.3$ & $14.8 \pm 1.2$ \\
\hline \multicolumn{5}{|l|}{ SW13 } \\
\hline Control & $1.8 \pm 0.3$ & $56.7 \pm 5$ & $15.9 \pm 0.9$ & $25.7 \pm 5.2$ \\
\hline Sirolimus $10^{-8} \mathrm{M}^{\mathrm{b}}$ & $1.9 \pm 0.6$ & $72.9 \pm 5.7^{\dagger}$ & $11.2 \pm 2.4^{\dagger}$ & $14 \pm 3.6^{\dagger}$ \\
\hline Sirolimus $10^{-10} \mathrm{M}^{\mathrm{b}}$ & $1.8 \pm 0.3$ & $67 \pm 6.2^{\dagger}$ & $14.4 \pm 1.7$ & $16.8 \pm 4.7^{\dagger}$ \\
\hline
\end{tabular}

${ }^{\star} P<0.05$ vs control; ${ }^{\dagger} P<0.001$ vs control.

${ }^{\mathrm{a} C e l l}$ cycle distribution measured after $72 \mathrm{~h}$ of incubation.

${ }^{\mathrm{b}}$ Cell cycle distribution measured after $24 \mathrm{~h}$ of incubation.

effects of the mTOR inhibitors. The antiproliferative effects of the drugs were observed at concentrations of sirolimus and temsirolimus that can be reached in vivo in humans (Atkins et al. 2004). Moreover, cell growth inhibition at these concentrations was considerably higher in SW13 than in H295 (and its clone HAC15). Many factors can contribute to this difference. SW13 cells differ from H295 because they harbor TP53 mutation (Forbes et al. 2008), they are less differentiated, they do not overproduce IGF2 and steroids, and they present a higher growth rate. Cells with TP53 mutation have been suggested to be more sensitive to mTOR inhibitors (Kurmasheva et al. 2006, Liu et al. 2009). The absence of the IGF2 overproduction can contribute to the higher sensitivity of SW13 cells compared with other two cell lines. The overstimulation of the growth factor receptors can determine the overactivation of the mTOR pathway upstream to mTOR (i.e. increased phosphorylation of AKT), or can overactivate other pro-growth pathways such as the RAS/RAF/MEK/ERK pathway (i.e. increased phosphorylation of ERK1/2), determining resistance or escape to the effects of traditional mTOR inhibitors (Easton et al. 2006, Wan et al. 2007, Zitzmann et al. 2007, Liu et al. 2009). We performed all our experiments using the same culture medium in all cell lines. In such a setting, the endogenous production of growth factor by the cells may determine differential sensitivity to mTOR inhibitors. The proliferation of H295 is stimulated by an autocrine/paracrine IGF2/ IGF1R loop (Logie et al. 1999). The overactivation of this loop can negatively influence the sensitivity of H295 to the mTOR inhibitors. This hypothesis is supported by the results obtained in western blotting (WB), the experiments using anti-IGF2 neutralizing
Abs and the colony-forming experiments. Using WB, we demonstrated that the effects of sirolimus on the IGF-activated intracellular pathways are different in H295 and SW13 cells. At the condition tested, IGF1 induced the activation of the AKT/mTOR pathway in both cell lines and ERK activation only in H295. Sirolimus suppressed the mTORC1 activity in both cell lines. However, in $\mathrm{H} 295$, but not in SW13, the inhibition of mTORC1 activity was associated with a significantly increased phosphorylation of AKT,

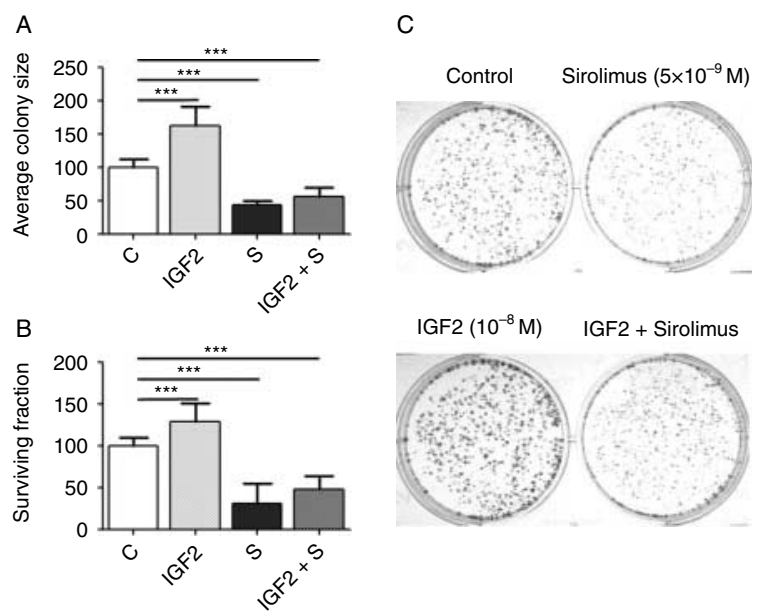

Figure 6 Effects of 3-week treatment with IGF2 $\left(10^{-8} \mathrm{M}\right)$ and/or sirolimus $\left(5 \times 10^{-9} \mathrm{M}\right)$ on colony formation and growth of the human ACC cell line H295. Left panel: IGF2 stimulates H295 cell proliferation by increasing the average size of colonies $(A)$ as well as the surviving fraction (B). Both these effects are efficiently antagonized by the coadministration of sirolimus. Data are expressed as percentage of control and represent the mean \pm s.D. Control is set as $100 \%$. The right panel (C) shows a representative photograph of the wells containing treated and untreated cells as used to perform colony-forming experiments. ${ }_{\star \star \star} \mathrm{P}<0.001$ vs control. 

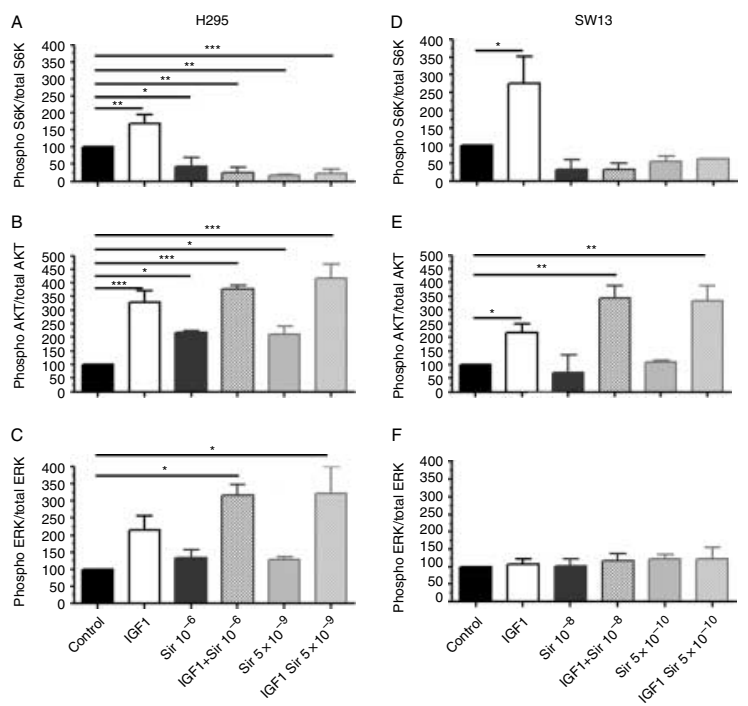

Figure 7 Western blotting results. In H295 ACC cell line (left panel): effects of sirolimus $\left(10^{-6}\right.$ and $\left.5 \times 10^{-9} \mathrm{M}\right)$ with/without IGF1 $\left(10^{-8} \mathrm{M}\right)$ administration on phospho-S6K/total S6K (A), phospho-ERK/total ERK (B), and phospho-AKT/total AKT (C). In SW13 ACC cell line (right panel): effects of sirolimus $\left(10^{-8}\right.$ and $\left.5 \times 10^{-10} \mathrm{M}\right)$ with/without IGF1 $\left(10^{-8} \mathrm{M}\right)$ administration on phospho-S6K/total S6K (D), phospho-ERK/total ERK (E), and phospho-AKT/total AKT (F). In the two ACC cell lines, the administration of sirolimus \pm IGF 1 induced different effects on IGF-activated intercellular pathways (explanation in the text). Protein activation is measured as the ratio of phosphoprotein band density/total protein band density. Values are expressed as percentage of the control, mean \pm S.D. ${ }^{\star} P<0.05 ;{ }^{* *} P<0.01$; ${ }^{* \star *} P<0.001$ vs control.

supporting an overactivation of the mTOR pathway upstream to mTORC1 in $\mathrm{H} 295$, likely representing an escape pathway. This activation could result by the IGF2 endogenous production that persistently stimulates the IGF1R (autocrine IGF loop) even in starved H295 cells. The effects of sirolimus on AKT were even enhanced by IGF1 administration, which also induced ERK stimulation in the sirolimus-treated H295, despite the fact that both basal and IGF1 S6K phosphorylation was fully blocked by sirolimus. These results show that in $\mathrm{H} 295$ cells treated with sirolimus, IGF can stimulate two pathways potentially associated with traditional mTOR inhibitors treatment escape: AKT and ERK pathways (Kurmasheva et al. 2006, Liu et al. 2009). To further provide evidence that in $\mathrm{H} 295$, the endogenous overproduction of IGF2 has a negative interference with the effects of mTOR inhibitors, we explored the effects of sirolimus alone or in the presence of anti-IGF2 neutralizing antibodies (at concentration predicted to effectively neutralize the endogenous IGF2 production). These experiments demonstrated for the first time that IGF2 neutralization increases the antiproliferative effects of mTOR inhibitors in an ACC model. This raises the question whether the cotreatment of traditional mTOR inhibitors and IGF1R antagonists should be considered for patients with ACCs known to have a strong IGF autocrine loop.

In colony-forming assay, H295 cells were more sensitive to sirolimus than observed with the DNA measurement. Possible mechanisms that could explain this higher sensitivity include the disruption of the growth factor paracrine/autocrine loops; the selection of 'aggressive clones', and the mTORC2 complex inhibition. In colony-forming experiments, the cell density is very low leading to the disruption of growth factor paracrine/autocrine loops and reducing the growth factor-induced activation of escape pathways. However, in the colony experiments, IGF2 (used at a dose comparable to the concentration reached in the medium of $\mathrm{H} 295$ in DNA-measurement experiments) stimulated cell proliferation but did not revert the effects of sirolimus, suggesting that IGF2 is not the only autocrine/paracrine regulator of the mTOR pathway activity in H295. By disrupting the autocrine/paracrine loops, we forced the cells to grow in a less favorable condition and this could lead to the selection of 'more aggressive clones'. H295 cells showed a low plating efficacy, suggesting that only a small percentage of cells are able to adapt and grow under these conditions. These cells could be less dependent by the autocrine/paracrine loops, less sensitive to the IGF2, and consequentially less exposed to the growth factor-induced activation of the escape

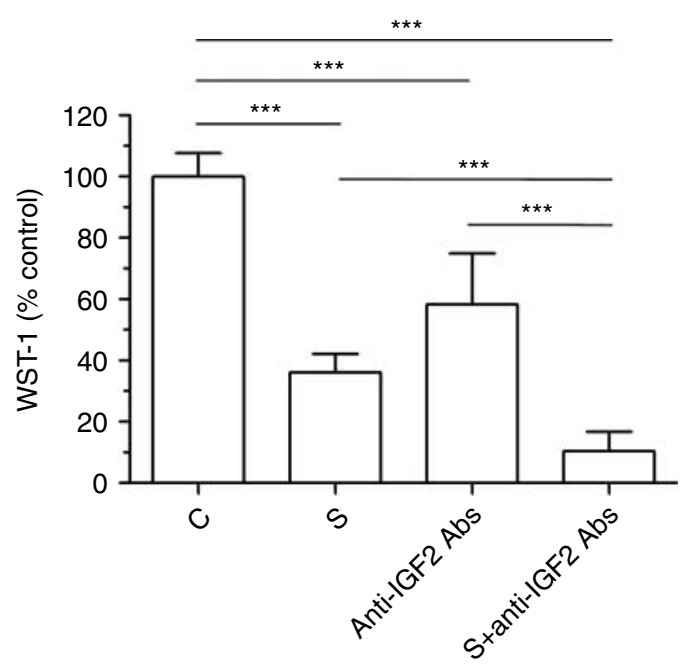

Figure 8 Effect of $72 \mathrm{~h}$ combination treatment with antiIGF2 neutralizing antibodies (anti-IGF2 Abs) at a concentration of $4 \times 10^{-8} \mathrm{M}$ and sirolimus (S, $10^{-9} \mathrm{M}$ ) on cell proliferation (WST-1) of $\mathrm{H} 295$ cells. Data are expressed as the percentage of control and represent the mean \pm s.D. Control is set as $100 \%$. ${ }^{\star \star \star} P<0.001$. 
pathways. This hypothesis could also contribute to explain the observed incapability of the IGF2 to revert the sirolimus-induced inhibition on H295 colony growth. Three weeks of continuous treatment of H295 cells with sirolimus induced a significant reduction of the cell-SF compared with controls. These results can suggest that longtime treatment with mTOR inhibitor does not only block the cell growth but also induce cell death. Traditional mTOR inhibitors such as sirolimus and temsirolimus have the mTORC1 complex as target. The presence of activated mTORC2 can stimulate the AKT activation representing a potential mechanism of escape to the effects of traditional mTOR inhibitors for cancer cells. However, it has been suggested that long-term treatment with traditional mTOR inhibitors can also indirectly inhibit the TORC 2 complex by sequestering mTOR as part of the TORC1 complex (Loewith et al. 2002, Hanna et al. 2008). This double block is considered as one of the potential mechanisms of mTOR inhibitor-induced tumor cell death (Liu et al. 2009). Moreover, mTORC2, as well as mTORC1, is activated by growth factors. Therefore, in colony experiments, the disruption of the autocrine/paracrine loops may also contribute to the mTORC2 inhibition (Sarbassov et al. 2005, Sabatini 2006). This raises the question whether the use of drugs simultaneously blocking mTORC1 and mTORC2 or mTORC1 and PI3K could have a place in the treatment of selected patients with ACCs.

For the first time, we show an antisecretive effect (inhibition of cortisol production) of mTOR inhibitors in ACC cell lines. The mechanisms responsible for this effect still need to be clarified. mTOR inhibitors are already used in the clinical setting and no signs or symptoms of hypoadrenalism have been described (Hudes et al. 2007). Therefore, it is probable that mTOR inhibitors are not able to suppress the physiological adrenal steroid production. The IGFs are able to stimulate adrenal steroid production. It is thus possible that mTOR could play a role as intracellular mediator of the effects of IGFs and that mTOR inhibition could antagonize this prosecretive effect of IGFs in ACC cells.

\section{Conclusions, translational aspects, and future directions}

The results of the current study suggest that ACCs may be considered for treatment with traditional mTOR inhibitors. The effects of these compounds in vitro at concentration potentially reachable in vivo are predominantly cytostatic, although it is shown that longtime treatment with traditional mTOR inhibitors (in conditions disrupting the autocrine loops) can lead to cell death. Additional clinical benefit in patients with hypersecretive ACCs could be an inhibitory effect of these compounds on cortisol secretion. However, several factors such as cell type, cell differentiation, the presence of an autocrine growth factor loop, as well as the cell environment could largely influence the sensitivity of ACCs to these drugs. These differences point out the importance to investigate the presence of biomarkers predictive of potential clinical benefit and to eventually proceed in the clinical investigation of these compounds only in selected patients with higher chance to respond to this treatment. This study also suggest to investigate the role of TP53 mutations, cell differentiation, proliferative index, the presence of activated autocrine loops as potential marker predictive of mTOR inhibitor effects in ACCs, and the activation of AKT and ERK during the treatment as potential markers of escape. Finally, it is suspected that in some cases of ACCs, combined treatment with mTOR inhibitors and other compounds should be considered to overcome possible mechanisms of resistance to mTOR inhibitors used as monotherapy.

Particularly, the effects of treatment targeting the IGF2 autocrine loop, in combination with mTOR inhibitors, warrant further investigation in ACC.

\section{Declaration of interest}

The authors declare that there is no conflict of interest that could be perceived as prejudicing the impartiality of the research reported.

\section{Funding}

This research did not receive any specific grant from any funding agency in the public, commercial, or not-for-profit sector.

\section{Acknowledgements}

Dr Dimiter Dimitrov and Dr Yang Feng kindly provided the anti-IGF2 antibody. Fadime Dogan and Claudia Pivonello kindly contributed to develop the protocol of the western blotting.

\section{References}

Allolio B \& Fassnacht M 2006 Clinical review: adrenocortical carcinoma: clinical update. Journal of Clinical Endocrinology and Metabolism 91 2027-2037. (doi:10.1210/jc.2005-2639)

Almeida MQ, Fragoso MC, Lotfi CF, Santos MG, Nishi MY, Costa MH, Lerario AM, Maciel CC, Mattos GE, Jorge AA 
et al. 2008 Expression of insulin-like growth factor-II and its receptor in pediatric and adult adrenocortical tumors. Journal of Clinical Endocrinology and Metabolism 93 3524-3531. (doi:10.1210/jc.2008-0065)

Atkins MB, Hidalgo M, Stadler WM, Logan TF, Dutcher JP, Hudes GR, Park Y, Liou SH, Marshall B, Boni JP et al. 2004 Randomized phase II study of multiple dose levels of CCI-779, a novel mammalian target of rapamycin kinase inhibitor, in patients with advanced refractory renal cell carcinoma. Journal of Clinical Oncology 22 909-918. (doi:10.1200/JCO.2004. 08.185)

Barlaskar FM, Spalding AC, Heaton JH, Kuick R, Kim AC, Thomas DG, Giordano TJ, Ben-Josef E \& Hammer GD 2009 Preclinical targeting of the type I insulin-like growth factor receptor in adrenocortical carcinoma. Journal of Clinical Endocrinology and Metabolism 94 204-212. (doi:10.1210/jc.2008-1456)

Baudin E, Leboulleux S, Al Ghuzlan A, Chougnet C, Young J, Deandreis D, Dumont F, Dechamps F, Caramella C, Chanson $\mathrm{P}$ et al. 2011 Therapeutic management of advanced adrenocortical carcinoma: what do we know in 2011? Hormones \& Cancer 2 363-371. (doi:10.1007/ s12672-011-0094-2)

Cantini G, Lombardi A, Piscitelli E, Poli G, Ceni E, Marchiani S, Ercolino T, Galli A, Serio M, Mannelli M et al. 2008 Rosiglitazone inhibits adrenocortical cancer cell proliferation by interfering with the IGF-IR intracellular signaling. PPAR Research 2008904041. (doi:10.1155/2008/904041)

De Martino MC, van Koetsveld PM, Pivonello R \& Hofland LJ 2010 Role of the mTOR pathway in normal and tumoral adrenal cells. Neuroendocrinology 92 (Suppl 1) 28-34. (doi:10.1159/000314280)

Doghman M, El Wakil A, Cardinaud B, Thomas E, Wang J, Zhao W, Peralta-Del Valle MH, Figueiredo BC, Zambetti GP \& Lalli E 2010 Regulation of insulin-like growth factor-mammalian target of rapamycin signaling by microRNA in childhood adrenocortical tumors. Cancer Research 70 4666-4675. (doi:10.1158/0008-5472.CAN09-3970)

Easton JB, Kurmasheva RT \& Houghton PJ 2006 IRS-1: auditing the effectiveness of mTOR inhibitors. Cancer Cell 9 153-155. (doi:10.1016/j.ccr.2006.02.027)

Fassnacht M, Libe R, Kroiss M \& Allolio B 2011 Adrenocortical carcinoma: a clinician's update. Nature Reviews. Endocrinology 7 323-335. (doi:10.1038/nrendo. 2010.235)

Feng Y, Zhu Z, Xiao X, Choudhry V, Barrett JC \& Dimitrov DS 2006 Novel human monoclonal antibodies to insulinlike growth factor (IGF)-II that potently inhibit the IGF receptor type I signal transduction function. Molecular Cancer Therapeutics 5 114-120. (doi:10.1158/15357163.MCT-05-0252)

Forbes SA, Bhamra G, Bamford S, Dawson E, Kok C, Clements J, Menzies A, Teague JW, Futreal PA \&
Stratton MR 2008 The Catalogue of Somatic Mutations in Cancer (COSMIC). Current Protocols in Human Genetics Chapter 10 Unit 1011.

Franken NA, Rodermond HM, Stap J, Haveman J \& van Bree C 2006 Clonogenic assay of cells in vitro. Nature

Protocols 1 2315-2319. (doi:10.1038/nprot.2006.339)

Guertin DA \& Sabatini DM 2007 Defining the role of mTOR in cancer. Cancer Cell 12 9-22. (doi:10.1016/j.ccr.2007. 05.008)

Hanna SC, Heathcote SA \& Kim WY 2008 mTOR pathway in renal cell carcinoma. Expert Review of Anticancer Therapy 8 283-292. (doi:10.1586/14737140.8.2.283)

Hofland LJ, van Koetsveld PM \& Lamberts SW 1990 Percoll density gradient centrifugation of rat pituitary tumor cells: a study of functional heterogeneity within and between tumors with respect to growth rates, prolactin production and responsiveness to the somatostatin analog SMS 201-995. European Journal of Cancer 26 37-44. (doi:10.1016/0277-5379(90)90254-Q)

Huang S \& Houghton PJ 2002 Inhibitors of mammalian target of rapamycin as novel antitumor agents: from bench to clinic. Current Opinion in Investigational Drugs 3 295-304.

Hudes G, Carducci M, Tomczak P, Dutcher J, Figlin R, Kapoor A, Staroslawska E, Sosman J, McDermott D, Bodrogi I et al. 2007 Temsirolimus, interferon alfa, or both for advanced renal-cell carcinoma. New England Journal of Medicine 356 2271-2281. (doi:10.1056/ NEJMoa066838)

Kerstens HM, Robben JC, Poddighe PJ, Melchers WJ, Boonstra H, de Wilde PC, Macville MV \& Hanselaar AG 2000 AgarCyto: a novel cell-processing method for multiple molecular diagnostic analyses of the uterine cervix. Journal of Histochemistry and Cytochemistry 48 709-718. (doi:10.1177/002215540004800515)

Konings IR, Verweij J, Wiemer EA \& Sleijfer S 2009 The applicability of mTOR inhibition in solid tumors. Current Cancer Drug Targets 9 439-450. (doi:10.2174/ 156800909788166556)

Kurmasheva RT, Huang S \& Houghton PJ 2006 Predicted mechanisms of resistance to mTOR inhibitors. British Journal of Cancer 95 955-960. (doi:10.1038/sj.bjc. 6603353)

Libe R \& Bertherat J 2005 Molecular genetics of adrenocortical tumours, from familial to sporadic diseases. European Journal of Endocrinology 153 477-487. (doi:10.1530/eje.1.02004)

Liu P, Cheng H, Roberts TM \& Zhao JJ 2009 Targeting the phosphoinositide 3-kinase pathway in cancer. Nature Reviews. Drug Discovery 8 627-644. (doi:10.1038/ nrd2926)

Loewith R, Jacinto E, Wullschleger S, Lorberg A, Crespo JL, Bonenfant D, Oppliger W, Jenoe P \& Hall MN 2002 Two TOR complexes, only one of which is rapamycin sensitive, have distinct roles in cell growth control. Molecular Cell 10 457-468. (doi:10.1016/S10972765(02)00636-6) 
Logie A, Boulle N, Gaston V, Perin L, Boudou P, Le Bouc Y \& Gicquel C 1999 Autocrine role of IGF-II in proliferation of human adrenocortical carcinoma NCI H295R cell line. Journal of Molecular Endocrinology 23 23-32. (doi:10.1677/jme.0.0230023)

LoPiccolo J, Blumenthal GM, Bernstein WB \& Dennis PA 2008 Targeting the PI3K/Akt/mTOR pathway: effective combinations and clinical considerations. Drug Resistance Updates 11 32-50. (doi:10.1016/j.drup.2007.11.003)

Pfaffl MW 2001 A new mathematical model for relative quantification in real-time RT-PCR. Nucleic Acids Research 29 e45. (doi:10.1093/nar/29.9.e45)

Rasmussen R 2001 Quantification on the LightCycler. In Rapid Cycle Real-time PCR, Methods and Applications, pp 21-34. Eds S Meuer, C Wittwer \& K Nagakawara. Heidelberg: Springer Press.

Sabatini AM 2006 Quaternion-based extended Kalman filter for determining orientation by inertial and magnetic sensing. IEEE Transactions on Biomedical Engineering 53 1346-1356. (doi:10.1109/TBME.2006.875664)

Sarbassov DD, Guertin DA, Ali SM \& Sabatini DM 2005 Phosphorylation and regulation of Akt/PKB by the rictormTOR complex. Science 307 1098-1101. (doi:10.1126/ science.1106148)

Schmittgen TD \& Livak KJ 2008 Analyzing real-time PCR data by the comparative $C(\mathrm{~T})$ method. Nature Protocols 3 1101-1108. (doi:10.1038/nprot.2008.73)
Volante M, Buttigliero C, Greco E, Berruti A \& Papotti M 2008 Pathological and molecular features of adrenocortical carcinoma: an update. Journal of Clinical Pathology 61 787-793. (doi:10.1136/jcp.2007.050625)

Wan X \& Helman LJ 2007 The biology behind mTOR inhibition in sarcoma. Oncologist 12 1007-1018. (doi:10.1634/theoncologist.12-8-1007)

Wan X, Harkavy B, Shen N, Grohar P \& Helman LJ 2007 Rapamycin induces feedback activation of Akt signaling through an IGF-1R-dependent mechanism. Oncogene 26 1932-1940. (doi:10.1038/sj.onc.1209990)

Wang T \& Rainey WE 2012 Human adrenocortical carcinoma cell lines. Molecular and Cellular Endocrinology 351 58-65. (doi:10.1016/j.mce.2011.08.041)

Zitzmann K, De Toni EN, Brand S, Goke B, Meinecke J, Spottl G, Meyer HH \& Auernhammer CJ 2007 The novel mTOR inhibitor RAD001 (everolimus) induces antiproliferative effects in human pancreatic neuroendocrine tumor cells. Neuroendocrinology 85 54-60. (doi:10.1159/ 000100057)

Received in final form 27 February 2012

Accepted 12 February 2012

Made available online as an Accepted Preprint 14 February 2012 